\title{
Room temperature reaction of oxygen with gold: an in situ ambient-pressure X-ray photoelectron spectroscopy investigation
}

\author{
Peng Jiang, ${ }^{\dagger, \ddagger}$ Soeren Porsgaard, ${ }^{\dagger, \S}$ Ferenc Borondics, "Mariana Köber, ${ }^{\dagger, \#}$ Alfonso Caballero, ${ }^{\dagger, \perp}$ Hendrik Bluhm, $\|$ \\ Flemming Besenbacher, ${ }^{\S}$ Miquel Salmeron ${ }^{*,+, \neq}$ \\ ${ }^{\dagger}$ Materials Sciences Division, Lawrence Berkeley National Laboratory, 1 Cyclotron Rd., Berkeley, California 94720 \\ ${ }^{*}$ Department of Materials Science and Engineering, University of California at Berkeley, CA 94720 \\ $\S$ Interdisciplinary Nanoscience Center (iNANO), Aarhus University, DK 8000 Aarhus C, Denmark \\ " Chemical Sciences Division, Lawrence Berkeley National Laboratory, 1 Cyclotron Rd., Berkeley, California 94720 \\ \# Instituto de Microelectrónica de Madrid, c/ Isaac Newton 8, 28760 Tres Cantos, Spain

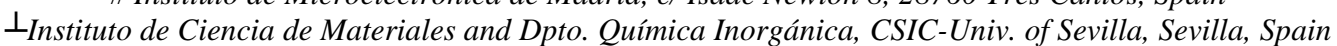

RECEIVED DATE (automatically inserted by publisher); * E-mail: MBSalmeron@lbl.gov

Gold is commonly regarded as the most inert element. ${ }^{1}$ However, the discovery of the exceptional catalytic properties of gold nanoparticles (NPs) for low temperature CO oxidation ${ }^{2}$ initiated great interest due to its promising applications and spawned a large number of studies devoted to the understanding of the reaction mechanism. ${ }^{3-6}$ Nevertheless, no consistent and conclusive picture has arisen. ${ }^{7-13}$

One of the most important and controversial issues is the activation mechanism of $\mathrm{O}_{2}$ on $\mathrm{Au} .^{9,14-19}$ For instance, based on the experimental observation that a bilayer Au structure, which completely wets the oxide support, exhibits extraordinary catalytic activity, Goodman et al. proposed that $\mathrm{Au}$ can be directly involved in the activation of $\mathrm{O}_{2} .{ }^{9}$ In contrast, more recently, Behm et al. found that the amount of active oxygen species on the $\mathrm{Au} / \mathrm{TiO}_{2}$ surface has a linear relationship with the number of perimeter sites at the interface between the oxide support and the $\mathrm{Au} \mathrm{NPs}$, indicating that the support-Au interface plays a dominating role in the oxygen activation. ${ }^{19}$ Furthermore, based on theoretical calculations, under-coordinated $\mathrm{Au}$ atoms were proposed to have the capability to adsorb and even dissociate $\mathrm{O}_{2}{ }^{14}$ Using high-intensity in situ X-ray absorption near-edge structure (XANES), van Bokhoven and co-workers observed an increased white line intensity at the $\mathrm{Au} \mathrm{L}_{3}$ edge for $\mathrm{Au}$ NPs supported on $\mathrm{Al}_{2} \mathrm{O}_{3}$ and $\mathrm{TiO}_{2}$ substrates during treatment in $\mathrm{O}_{2}$, indicating that $\mathrm{Au}$ NPs can be oxidized by molecular oxygen. ${ }^{17,18}$ However, Liu et al. calculated that the dissociation barrier is larger than $2 \mathrm{eV}$ on non-supported $\mathrm{Au}$ and even at the $\mathrm{Au} / \mathrm{TiO}_{2}$ interface the dissociation barrier is still $0.52 \mathrm{eV},{ }^{15}$ which means that $\mathrm{O}_{2}$ has a very weak interaction with $\mathrm{Au}$, and thus spontaneous dissociation of molecular oxygen on the $\mathrm{Au}$ surface is not energetically favorable.

In order to reconcile these controversial observations and proposals we investigated the reactivity of $\mathrm{O}_{2}$ with bulk $\mathrm{Au}$ foil and $\mathrm{Au}$ NPs supported on $\mathrm{TiO}_{2}(110)$ surface using in situ Ambient Pressure X-ray Photoelectron Spectroscopy (AP-XPS) at $\mathrm{O}_{2}$ pressures of up to 1 Torr. $^{20,21}$ Our data demonstrate that molecular oxygen does not have a strong interaction with $\mathrm{Au}$ surfaces at room temperature. However, we observed that molecular oxygen can be activated on both types of samples by $\mathrm{X}$ ray irradiation to produce oxidic $\mathrm{Au}$. We further investigated and compared the stability of oxidized Au on both model systems.
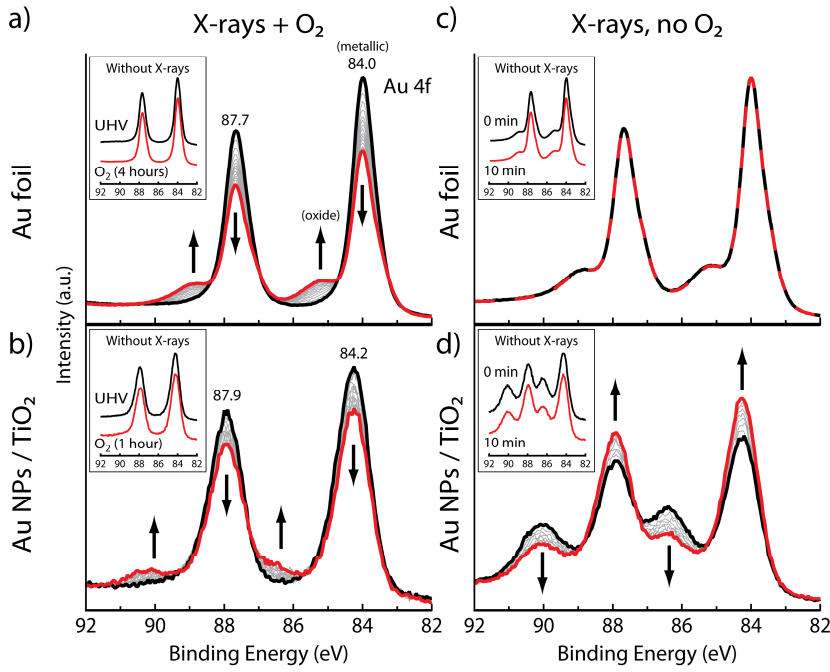

Figure 1. Time evolution of the XPS spectra of $\mathrm{Au} 4 \mathrm{f}$ under X-ray irradiation at room temperature. (a) $\mathrm{Au}$ foil and (b) $\mathrm{Au}$ NPs on $\mathrm{TiO}_{2}$ support in the presence of 1 Torr $\mathrm{O}_{2}$. (c) Oxidized $\mathrm{Au}$ foil and (d) oxidized $\mathrm{Au}$ NPs on $\mathrm{TiO}_{2}$ support in UHV. The peaks on the higher energy binding side of the metallic $4 \mathrm{f}_{7 / 2}$ and $4 \mathrm{f}_{5 / 2}$ peaks are due to oxidized gold. The bold black and red curves correspond to the first and the last spectrum, respectively. The arrows indicate the direction of the intensity changes. The insets show the $\mathrm{Au}$ 4f spectra from the test experiments under similar condition, but without X-ray irradiation for the specified time.

The experiments were performed at beam line 11.0.2 of the Advanced Light Source (ALS) at Lawrence Berkeley National Laboratory. ${ }^{20,21}$ This system consists of a preparation chamber and an AP-XPS analysis chamber with base pressure of $3 \times 10^{-10}$ Torr. The $\mathrm{Au}$ foil and the $\mathrm{TiO}_{2}(110)$ single crystal samples were cleaned by several cycles of $\mathrm{Ar}^{+}$sputtering and annealing. Au NPs were obtained by thermal evaporation of $\mathrm{Au}$ onto the $\mathrm{TiO}_{2}(110)$ surface at $320 \mathrm{~K}$, following a procedure described in the literature. ${ }^{22}$ The amount of deposited Au was calibrated by the ratio between $\mathrm{Au} 4 \mathrm{f}$ and $\mathrm{Ti} 2 \mathrm{p}$ peaks. $\mathrm{O}_{2}$ gas was dosed through a leak valve. A photon energy of $690 \mathrm{eV}$ was used to acquire all the spectra. The binding energy scale was calibrated by using the metallic $\mathrm{Au} 4 \mathrm{f}_{7 / 2}$ (binding energy $84.0 \mathrm{eV}$ ) peak and the Fermi 
edge of $\mathrm{Au}$ foil as references. The photon flux density was approximately $4 \times 10^{12}$ photons $\mathrm{mm}^{-2} \mathrm{~s}^{-1}$.

The insets in Figures $1 \mathrm{a}$ and $1 \mathrm{~b}$ show the $\mathrm{Au} 4 \mathrm{f}$ spectra obtained from the gold foil and from a 0.3 ML (monolayer) of $\mathrm{Au}$ on $\mathrm{TiO}_{2}$ under UHV and under 1 Torr of $\mathrm{O}_{2}$, respectively. In comparison with bulk $\mathrm{Au}$ foil $(84.0 \mathrm{eV})$, the $\mathrm{Au} 4 \mathrm{f}_{7 / 2}$ peak of the submonolayer deposit shifts to a higher binding energy $(84.2 \mathrm{eV})$, due to a combination of initial and final state effects. ${ }^{23,24}$ After exposure to $\mathrm{O}_{2}$ at 1 Torr for several hours in the absence of $\mathrm{X}$ rays, both peak position and width remain the same. These results demonstrate that $\mathrm{O}_{2}$ does not have a strong interaction with $\mathrm{Au}$, both in bulk form and in the form of NPs, under the above conditions. This observation is consistent with the known inertness of $\mathrm{Au}$, which originates from the filled d-band structure. ${ }^{1}$

However, we observed that under X-ray irradiation in the presence of oxygen gas, the Au surfaces could be oxidized. Figures $1 \mathrm{a}$ and $1 \mathrm{~b}$ show the time evolution of the $\mathrm{Au} 4 \mathrm{f}$ region under irradiation of X-rays in the presence of 1 Torr of $\mathrm{O}_{2}$ over 15 minutes. On the foil the intensity of the metallic $\mathrm{Au} 4 \mathrm{f}$ peaks ( $\mathrm{Au}$ $4 \mathrm{f}_{7 / 2} 84.0 \mathrm{eV}$ and $\mathrm{Au} 4 \mathrm{f}_{5 / 2} 87.7 \mathrm{eV}$ ) decreases with time, while at the same time two additional peaks appear, which are shifted by $1.3 \mathrm{eV}$ to higher binding energies relative to the metallic $\mathrm{Au} 4 \mathrm{f}$ peaks. Previous studies have reported similar peak shifts for oxidized $\mathrm{Au}$ surfaces prepared using different oxidation methods. ${ }^{25-28}$ On the Au NPs formed by evaporation on the $\mathrm{TiO}_{2}$ crystal, two additional peaks develop also at the higher binding energy side that can be attributed to oxide as well. It is noteworthy to mention that both the oxidation rate and the chemical shift of the oxide peaks depend strongly on the size of $\mathrm{NPs},{ }^{28-30}$ which is still under further investigation.

$\mathrm{X}$-ray induced formation of chemisorbed oxygen species have been reported previously. ${ }^{31,32}$ However, these measurements were carried out under ultrahigh vacuum at temperatures below $30 \mathrm{~K}$, where chemisorbed oxygen is produced from physisorbed molecular oxygen. Therefore, both the experiment conditions and the activation process are dramatically different from the ambient conditions in this communication.

The stability of the oxidic $\mathrm{Au}$ species formed in this way was subsequently investigated also under X-ray irradiation. We found that the two samples show different behaviors. While the oxidic $\mathrm{Au}$ in the NPs on $\mathrm{TiO}_{2}(110)$ could be readily reduced under x-ray irradiation, the oxidic $\mathrm{Au}$ film formed at the surface of the foil was resistant to X-ray irradiation. This is shown in Figs. 1c and $1 \mathrm{~d}$, where the spectra were recorded sequentially during 10 minutes. The difference in reduction behavior lends support to the oxygen spillover model proposed by Ono and Cuenya ${ }^{33}$ based on the well-known facile reducibility of the $\mathrm{TiO}_{2}$ support. Under Xray irradiation, oxygen vacancies can be generated on the $\mathrm{TiO}_{2}$ surface. ${ }^{34}$ For the NP sample oxygen can spill from the oxidized $\mathrm{Au} \mathrm{NP}$ to the reducible $\mathrm{TiO}_{2}$ substrate, while this reduction channel is not available for bulk gold. The different reduction behavior makes it difficult to compare the oxidation rate of the two samples during X-ray induced oxidation because for Au NPs the oxidation and reduction processes induced by X-rays take place simultaneously. To exclude any effect related to the UHV condition alone, we have investigated the stability of the oxidic species under UHV without X-ray irradiation. As shown in the insets of Figs. 1c and 1d, both samples are stable after 10 minutes under UHV in the absence of the X-ray beam.

In summary, using AP-XPS we have demonstrated that molecular oxygen does not oxidize Au at room temperature, either in the form of supported NPs on $\mathrm{TiO}_{2}(110)$ or in bulk (foil) form at pressures of up to 1 Torr. These observations indicate that the proposed gold-only activation mechanism of $\mathrm{O}_{2}$ is unlikely under these reaction conditions. ${ }^{8,13,15,16,19}$ With the help of X-ray irradiation, however, both surfaces can be effectively oxidized under 1 Torr of $\mathrm{O}_{2}$. Therefore, our observations demonstrate that $\mathrm{X}$-rays play a critical dual role during in situ measurements and that extreme care must be taken to carry out experiments and interpret spectra, especially when using intense synchrotron radiation.

Acknowledgement. This work was supported by the Director, Office of Science, Office of Basic Energy Sciences, Chemical Sciences, Geosciences, and Biosciences Division, under the Department of Energy Contract No. DE-AC02-05CH11231. S.P. acknowledges the Carlsbergs Mindelegat foundation for financial support. M.K. was supported by the Spanish Council for Scientific Research through an I3P scholarship. We also thank Dr. Jinghua Guo and Dr. Zhi Liu for their helpful discussions.

\section{REFERENCES}

(1) Hammer, B.; Nørskov, J. K. Nature 1995, 376, 238.

(2) Haruta, M.; Kobayashi, T.; Yamada, N. Chem. Lett. 1987, 2, 405.

(3) Haruta, M. Catal. Today 1997, 36, 153.

(4) Daniel, M. C.; Astruc, D. Chem. Rev. 2004, 104, 293.

(5) Hashmi, A. S. K.; Hutchings, G. J. Angew. Chem., Int. Ed. 2006, 45, 7896 (6) Kung, M.C.; Davis, R. J.; Kung, H. H. J. Phys. Chem. C 2007, 111, 11767. (7) Valden, M.; Lai, X.; Goodman, D. W. Science 1998, 281, 1647.

(8) Schubert, M. M.; S. Hackenberg, van Veen, A. C.; Muhler, M.; Plzak, V.; Behm, R. J. J. Catal. 2001, 197, 113.

(9) Chen, M. S.; Goodman, D. W. Science 2004, 306, 252

(10) Lemire, C.; Meyer, R,; Shaikhutdinov, S.; Freund, H. J. Angew. Chem., Int. Ed. 2004, 43, 118 .

(11) Yoon, B.; Hakkinen, H.; Landman, U.; Worz, A. S.; Antonietti, J. M.; Abbet, S.; Judai, K.; Heiz, U. Science 2005, 307, 403.

(12) Herzing, A. A.; Kiely, C. J.; Carley, A. F.; Landon, P.; Hutchings, G. J Science 2008, 321, 1331 .

(13) Matthey, D.; Wang, J. G.; Wendt, S.; Matthiesen, J.; Schaub, R.; Lægsgaard, E.; Hammer, B.; Besenbacher, F. Science, 2007, 315, 1692.

(14) Lopez, N.; Nørskov, J. K. J. Am. Chem. Soc. 2002, 124, 11262.

(15) Liu, Z. P.; Gong, X. Q.; Kohanoff, J.; Sanchez, C.; Hu, P. Phys. Rev. Lett. 2003, $91,266102$.

(16) Hernández, N.C.; Sanz, J. F.; Rodriguez, J. A. J. Am. Chem. Soc. 2006 128,15600 .

(17) van Bokhoven, J. A.; Louis, C.; Miller, J. T.; Tromp, M.; Safonova, O V.; Glatzel, P. Angew. Chem., Int. Ed. 2006, 45, 4651.

(18) Weiher, N.; Beesley, A. M.; Tsapatsaris, N.; Delannoy, L.; Louis, C.; van Bokhoven, J. A., Schroeder, S. L. M. J. Am. Chem. Soc. 2007, 129, 2240.

(19) Kotobuki, M.; Leppelt, R.; Hansgen, D. A.; Widmann, D.; Behm, R. J. J. Catal. 2009, 264, 67.

(20) Ogletree, D. F.; Bluhm, H.; Hebenstreit, E. D.; Salmeron, M. Nucl. Instrum. Meth. A 2009, 601, 151 .

(21) Salmeron, M.; Schlogl, R. Surf. Sci. Rep. 2008, 63, 169

(22) Lai, X.; St Clair, T. P.; Valden, M.; Goodman, D. W. Prog. Surf. Sci. 1998, 59, 25 .

(23) Mason, M. G. Phys. Rev. B 1983, 27, 748.

(24) Wertheim, G. K.; DiCenzo, S. B.; Youngquist. S. E. Phys. Rev. Lett. 1983, 51,2310 .

(25) Pirezux, J. J.; Liehr, M.; Thiry, P. A.; Delrue, J. P.; Caudano, R. Surf. Sci. 1984, 141,221

(26) Canning, N. D. S.; Outka, D.; Madix, R. J. Surf. Sci. 1984, 141, 240.

(27) King, D. E. J. Vac. Sci. Technol. A 1995, 13, 1247.

(28) Boyen, H. G.; Kastle, G.; Weigl, F.; Koslowski, B.; Dietrich, C. Ziemann, P.; Spatz, J. P.; Reithmuller, S.; Hartmann, C.; Moller, M.; Schmid G.; Garnier, M. G.; Oelhafen, P. Science 2002, 297, 1533.

(29) Cuenya, B. R.; Baeck, S. H.; Jaramillo, T. F.; McFarland, E. W. J. Am. Chem. Soc. 2003, 125, 12928.

(30) Lim, D. C.; Lopez-Salido, I.; Dietsche, R.; Bubek, M.; Kim, Y. D. Angew. Chem., Int. Ed. 2006, 45, 2413.

(31) Gottfried, J. M.; Schmidt, K. J.; Schroeder, S. L. M.; Christmann, K. Surf. Sci. 2002, 511, 65.

(32) Kim, J.; Dohnálek, Z.; Kay, B. D. J. Am. Chem. Soc. 2005, 127, 14592.

(33) Ono, L. K.; Cuenya, B. R. J. Phys. Chem. C 2008, 112, 4676.

(34) Locatelli, A.; Pabisiak, T.; Pavlovska, A.; Mentes, T. O.; Abelle, L.; Kiejna, A.; Bauer, E., J. Phys.: Condens. Matter 2007, 19, 82202. 
Insert Table of Contents artwork here

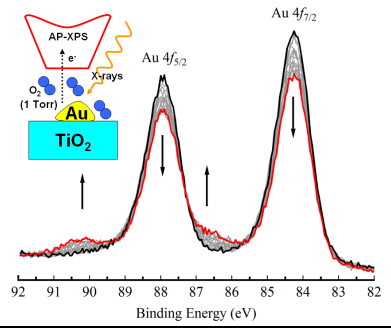

The interaction of $\mathrm{O}_{2}$ with gold foil and gold nanoparticles grown by thermal deposition on $\mathrm{TiO}_{2}(110)$ was studied by in situ Ambient Pressure X-ray Photoelectron Spectroscopy (AP-XPS) at room temperature. No spontaneous dissociation of $\mathrm{O}_{2}$ was observed either on $\mathrm{Au}$ foil or on $\mathrm{Au}$ nanoparticles up to 1 Torr of $\mathrm{O}_{2}$. X-ray irradiation, however, is very effective in promoting gold oxidation on both surfaces in the presence of $\mathrm{O}_{2}$. Our results help reconcile recent conflicting experimental observations regarding the activation of molecular oxygen, which is a crucial issue in Au catalyzed oxidation reactions. 